\title{
Research Progress on the Mechanism of Alfalfa Cold Resistance During Overwintering Period
}

\author{
Wu Jiabin ${ }^{1,2, ~ *, ~ M i a o ~ S h u ², ~ Z h a n g ~ R u i q i a n g ~}{ }^{2}$, Miao Henglu², Wang Sen ${ }^{1}$ \\ ${ }^{1}$ School of Life Sciences, Inner Mongolia University, Hohhot, China \\ ${ }^{2}$ Institute of Water Resources for Pastoral Area, MWR, Hohhot, China

\section{Email address:} \\ mkswjb@163.com (Wu Jiabin), miaoshu@vip.sina.com (Miao Shu),764040433@qq.com (Zhang Ruiqiang), \\ 1143889464@qq.com (Miao Henglu),2998222713@qq.com (Wang Sen)
}

\section{To cite this article:}

Wu Jiabin, Miao Shu, Zhang Ruiqiang, Miao Henglu, Wang Sen. Research Progress on the Mechanism of Alfalfa Cold Resistance During Overwintering Period. Agriculture, Forestry and Fisheries. Vol. 4, No. 6, 2015, pp. 300-304. doi: 10.11648/j.aff.20150406.21

\begin{abstract}
Understanding and research on the mechanism of alfalfa cold resistance has become one of the hot spots in grassland and pasture accompany the rapid development of the scale of feeding grassland construction. This paper expounds the origin of damage to the alfalfa caused by low temperature stress in winter, and summarizes the physiological and biochemical changes of alfalfa and its cold resistance, and discusses the countermeasures to improve the cold resistance of Alfalfa from three aspects: variety selection and cold resistance breeding, cultivation and management, genetic engineering. The prospect of future research on improving cold resistance of alfalfa was discussed.
\end{abstract}

Keywords: Alfalfa, Cold Resistance, Mechanism, Research Progress

\section{紫花苜蓿越冬期抗寒机理研究进展}

鸟佳宾 ${ }^{1,2, *}$, 苗澍 ${ }^{2}, 弓$ 瑞强 ${ }^{2}$, 苗恒录 ${ }^{2}$, 王森 $^{1}$

${ }^{1}$ 生命科学学院, 内蒙古大学, 内蒙古, 呼和浩特, 中国

灌溉与排水技术研究室, 水利部牧区水利科学研究所, 内蒙古, 呼和浩特, 中国

\section{邮箱}

mkswjb@163. com(邬佳宾), miaoshu@vip. sina. com(苗澍), 764040433@qq.com(张瑞强), 1143889464@qq. com(苗恒录), 2998222713@qq. com(王森)

摘要：伴随着饲草地建设规模的迅猛发展，认识和研究紫花苜宿越冬期抗寒机理，已经成为草原牧区研究热点之一。 阐述越冬期低温胁迫对苜宿造成损害的成因，总结和归纳低温胁迫下苜宿生理生化变化及其抗寒性能力，从品种选择 和抗寒育种、栽培管理综合技术、基因工程三个方面探讨了增强苜宿抗寒能力的措施，并对提高苜宿抗寒性研究进行 了展望。

关键词: 紫花苜宿, 抗寒性, 机理, 研究进展

1. 引言

紫花苜宿（Medicago satica L) 作为一种多年生豆 科优质牧草，因其具有适应性好、品质良好、抗逆性好、 产量高等特点, 在畜牧业生产中占据了重要的地位。多年
生牧草越冬期低温造成的冻害是生产上的一大威胁, 不仅 影响苜宿草地的持续高效利用, 而且限制了栽培区域的发 展。近年来, 气候异常变化加剧, 局部地区冻旱灾害呈多 发态势, 在中国北方草原牧区表现的尤为突出。中国内蒙 古自治区提出到2020年发展1000万亩节灌饲草地, 新疆、 
西藏也提出发展目标。伴随着饲草地建设规模的迅猛发展, 认识和研究紫花苜䔤越冬期抗寒机理, 已经成为草原牧区 研究热点之一。

\section{2. 越冬期低温胁迫与抗寒性}

温度是限制植物地理分布的重要因素, 适宜的温度是 决定植物能否生存的必要条件。紫花苜宿作为重要的冷季 型牧草, 广泛分布于中国北方及南北气候过渡区, 越冬期 的低温胁迫是影响其安全越冬的主要环境因素 [1-3]。

低温胁迫造成的寒害又可以分为冷害与冻害。冷害是 $0^{\circ} \mathrm{C}$ 以上的低温对植物造成的危害, 是直接由于低温造成 的损害, 以植物细胞膜损害为主。细胞膜是植物与外界环 境联系的界面, 是细胞乃至植物赖以生存的基础。植物遭 受冷害后出现各种代谢变化, 当膜脂发生降解时, 就可能 出现组织受害甚至植株死亡。冻害是指温度低于 $0{ }^{\circ} \mathrm{C}$, 会 引起植物体内水分结冰, 冰晶体会破坏细胞质膜和液泡膜, 严重影响细胞正常代谢, 造成植株损伤或死亡。研究表明, 冻害造成的植物伤害和死亡, 大部分是由于细胞间隙结冰 所致 [4-6]。

在一定的低温胁迫范围内, 多年生植物形成了适应环 境胁迫的生理抗性, 通过自身的变异和自然选择, 获得的 一种抗寒性。这种抗寒性在生长季最小, 晚秋通过抗寒锻 炼逐渐提高, 冬季最高, 春天气温回升后又逐渐消失。苜 宿抗寒性的强弱与诸多因素有关, 在植物自身方面, 品种、 遗传、叶片形态、根系类型、发育状况等都与抗寒性密切 相关; 同时种植及田间管理、土壤温度水分状况、雪被、 倒春寒、坡向、光照等外部环境因素, 也对苜宿越冬期抗 寒性起着关键作用 [7-15]。所以从不同角度入手, 综合多 方面因素研究抗寒性也是未来的研究方向之一 [16]。

\section{3. 苜蕧生理生化变化与其抗寒性}

苜宿作为一种抗寒性较强的植物品种, 当受到低温胁 迫时, 其酶活性、渗透调节物质、植物激素等生理生化指 标都会发生明显变化。

\section{1. 保护性酶与抗寒性}

苜宿收到低温胁迫时细胞会产生和积累大量生物氧 自由基, 这些物质的过度累积会损伤膜系统, 最终导致细 胞功能的丧失甚至植株死亡。苜宿体内保护酶系统通过清 除活性氧和自由基来增强其抗性和免于逆境伤害。过氧化 物酶、超氧化物歧化酶、过氧化氢酶是苜宿体内重要的三 种保护酶, 它们能消除生物氧自由基造成的伤害, 维持细 胞膜稳定。酶活性的大小可反映出苜宿抗寒性的强弱。

\subsection{1. 过氧化物酶}

过氧化物酶（Peroxidase, 简称POD）广泛存在与生 物体内, 可将生物体内有害过氧化物转化为无害氧化物。 其活性程度及增幅大小直接关系到植物细胞的损伤程度, 因此可用其确定植物抗逆性的强弱。通常抗寒性强的品种 过氧化物酶活性高, 对环境反应快, 抗冻能力强 [17]。研
究表明, 抗寒性较强的品种通过提高的POD活性来增加植 物体的抗寒性, 从而减轻低温胁迫对植物体的伤害 [18]; 受低温胁迫的紫花苜宿, 其两条POD同工酶区带的活性增 加 [17]; 秋冬随温度的降低, 苜宿POD同工酶谱带和活性 明显增加, 有利于及时清除细胞内的有害物质, 保护生物 膜不受损害 [19]。

\subsection{2. 超氧化物歧化酶}

超氧化物歧化酶 (Superoxide dismutase, 简称SOD) 是植物抗氧化系统的第一道防线, 是酶促清除系统的核心 酶。逆境中的许多植物, 其体内SOD的活性都发生了变化 [20], 当然苜宿也不例外。罗新义等在对肇东苜宿的研究 中发现, 低温胁迫诱发SOD酶活性上升, 当低温持续一段 时间后, 活性下降但仍具有较高活性, 这可能是SOD保护 酶已形成一定的耐寒机制, 使活性氧代谢处于平衡状态, 从而降低了细胞膜的破坏程度 [21]。邓雪柯等研究低温胁 迫下紫花苜宿的幼苗的生理生化变化, 表明苜宿植株可以 通过提高SOD酶活性以减少低温胁迫产生的自由基的伤害 [22]。可见, SOD的高活性避免了活性氧自由基的大量积 累, 有利于苜宿细胞膜的稳定, 从而提高苜宿的抗寒性。

\section{1. 3. 过氧化氢酶}

过氧化氢酶 (catalase, 简称CAT) 普遍存在与植物 组织中, 其活性与植物的代谢强度及抗寒能力有一定关系。 低温胁迫条件下, 植物体内的活性氧会加强代谢, 使得过 氧化氢 $\left(\mathrm{H}_{2} \mathrm{O}_{2}\right)$ 得以积累, $\mathrm{H}_{2} \mathrm{O}_{2}$ 能够破坏核酸和蛋白质等大 分子结构, 破坏细胞膜, 加速细胞的衰老和解体, 而CAT 能够清除细胞中 $\mathrm{H}_{2} \mathrm{O}_{2}$ 。研究表明, 低温处理后, 植物中的 CAT活性强, 则可增强其在低温胁迫时的抗逆能力, 提高 了低温存活率 [23]。因此苜宿组织中CAT活性与其抗寒性 密切相关。

\section{2. 渗透调节物质与抗寒性}

在低温胁迫环境下, 苜宿体内积累各种渗透调节物质, 使植株具有渗透调节的能力。植物在环境胁迫下, 通过细 胞内代谢活动, 合成某些对原生质无伤害的渗透调节物质 从而降低水势以平衡周围环境的胁迫。在低温胁迫下, 细 胞膜透性增大使细胞内大量物质渗出, 此时苜宿细胞内代 谢加强, 合成渗透调节物质降低细胞渗透势从而减轻细胞 伤害。

\subsection{1. 可溶性糖}

植物体受低温胁迫初期, 细胞内可溶性糖含量的增加 可帮助其适应低温环境 [24]。伴随环境温度下降, 苜宿细 胞内大分子物质发生水解从而增加可溶性糖, 可溶性糖含 量越大苜宿的抗寒能力越强。苜宿根及根颈中可溶性糖的 积累与其抗寒及越冬性呈显著的正相关 [25]。

\subsection{2. 游离脯氨酸}

处于低温等逆境时, 植物体会积累数量与植物抗逆性 相关的游离脯氨酸。植物体内的游离脯氨酸进行有效的渗 透调节作用, 维持原生质与环境的渗透平衡, 以保持细胞 内环境的相对稳定。苜宿植株体内脯氨酸的含量增加有利 
于提高其抗寒性 [26], 并且随着低温胁迫时间的延长, 苜 葆体内游离脯氨酸绝对含量逐渐增加 $[21]$ 。可见脯氨酸含 量是一种衡量苜宿抗寒性的重要生理生化指标。

\subsection{3. 丙二醛}

苜葆在逆境中收到伤害, 伴随发生膜脂过氧化作用, 丙二醛 (malondialdehyde, MDA) 是这一作用的最终分解 产物, 因此越冬期苩葆根部的MDA含量能够代表膜脂过氧 化的程度, 从而间接反映苜葆抗寒能力的强弱。以内蒙古 赤峰市林西县为例, 9 月份气温下降, 个苜宿品种根部积 累大量的MDA, 而后由于苜芿经过抗寒锻炼, 体内的抗寒 机制逐渐启动, 低温保护物质开始增加, 从而控制了细胞 内膜脂过氧化, 减小了低温对膜脂的损害, MDA含量降低; 1月份以后, 可能由于低温保护物质逐渐减少及其他抗氧 化保护作用减弱, MDA含量又开始逐渐升高 [27]。

\section{3. 植物激素与抗寒性}

低温胁迫下植物内源激素的变化与抗寒性密切相关, 这些激素包括脱落酸（Abscisic acid, ABA) 、水杨酸

(Salicylic acid, SA)、赤霉素 (Gibberellin, GA) 等。尽管存在争议, 但很多研究均表明, 植物抗寒性是 不同激素协同作用的结果。低温胁迫下紫花苜宿的试验 结果表明, ABA更多的参与了萛宿体内脯氨酸的合成、代 谢与转运, SA则更多的与苜葆体内可溶性糖等糖类物质 相互促进 [28]。在苜宿、冬小麦等多种植物研究中发现, 低温可以降低GA水平, 是植株生长速度减慢以适应越冬 期的低温。

\section{4. 根系活力}

根系是牧草重要的吸收器官和合成器官, 根系的生长 状况及其活力水平直接影响牧草的品质和产量。苜葆作为 宿根牧草, 主要依赖根部的活力渡过越冬期, 所以, 苜宿 根系活力在很大程度上不仅能衡量其生长状况, 更能反映 出植株抗寒性的强弱。研究表明, 宿根花卉、野牛草、玉 秠等植物在低温胁迫下 [29-31], 根系活力均与植物抗寒 性呈显著的相关关系。可见根系活力是衡量植物抗寒性的 重要指标, 并且实践中应结合更多的抗寒指标, 综合评价 和判断植物抗寒性。

\section{4. 增强苜蓿抗寒能力的措施}

\section{1. 适宜品种选择与抗寒育种}

因地制宜的选择苜葆品种是保证苜宿安全越冬的首 要条件, 在中国北方寒冷地区, 品种的选择应首先考虑秋 眠级和抗寒性。秋眠级高的品种再生株高度高, 对应产量 高, 但其抗寒能力弱, 越冬期损伤重, 反之亦然。因此根 据生产目标、当地气候条件、现场调查、引种试验等多方 面因素综合分析, 确定适宜品种, 才能保证苜宿安全越冬。 中国苜宿品种来源主要有三个方面, 分别是地方品种、国 外引进品种以及国内育成品种。利用田间选择、回交、杂 交, 通过连续多代选择, 可以显著提高苜葆品种的抗寒性。
科研和生产已经证明, 培育抗寒优良品种, 是减轻植物冻 害的有效手段和根本途径, 对提高植物抗寒性非常重要, 也非常有潜力, 但是育种周期较长, 成本较高。

\section{2. 栽培管理综合技术}

常见的提高苜宿抗寒能力的栽培管理技术有适时早 播、合理刈割和冬春季田间管理。适时早播增加了苜葆生 长时间, 根颈粗, 扎根深, 有利于根系物质量与养分的积 累, 提高了苜葆越冬期抗寒能力。苜葆每年刈割 $2 \sim 3$ 次, 最后一次刈割时间对苜葆越冬影响较大, 一般应在霜冻前 4 6周进行, 以便苜宿积累足够的养分越冬。刏割留茬高 度与苜宿的越冬率成正比, 但留茬过高会影响末茬草产量, 留茬高度应该在 $5 \sim 10 \mathrm{~cm}$ 之间。冬春季田间管理是保证和 提高苜宿越冬率的重要措施之一, 主要内容有入冬前灌封 冻水, 春季解冻后灌化冻水, 通过覆土、覆肥等措施增加 保温层, 消除鼠虫病害, 喷施防冻剂等。栽培管理技术的 综合应用可为苜宿越冬创造良好的生境条件, 从而增强抗 寒能力, 促进苜宿安全越冬。

\section{3. 基因工程}

基因工程是以分子遗传学为理论基础, 将分子生物学 和微生物学的现代方法作为手段, 将不同来源的基因按通 过载体导入活性细胞中, 从而改变生物原有的遗传特性, 对生物进行改造。分子水平上提高苜宿的抗寒性可以快速 的改良现有品种, 提高其抗寒性。研究发现, 低温锻炼能 够诱导和增强植物一些基因的表达，并使多种基因表达发 生改变, 国际植物抗寒基因工程主要从导入抗寒调控基因 和导入抗寒功能基因两方面开展研究 [32], 苜葆也不例外。 研究发现, $\mathrm{CBF} 1$ 转录激活因子是一类受低温特异诱导的 反式作用因子, 能与CRT/DRE调控元件结合, 促进低温胁 迫诱导基因的表达，并激活植物体内的多种耐逆机制。 徐春波等成功构建了含有AtCBF1基因的表达载体，导入 紫花苜宿进行遗传转化, 并获得了抗寒性转化植株 [33]。 Brouwer [34] 等将Mn-SOD基因导入紫花苜宿, 发现转基因 植株SOD活性增强, 越冬率平均提高25\%, McKersie [35] 等、Samis [36]等也得到了类似的研究成果。抗寒功能基 因Mn-SOD的导入和表达, 直接增强了苜荏的抗氧化能力, 细胞膜的稳定性、植株抗逆性均明显提高。苜宿抗寒性 是多种基因协同表达的结果, 同时抗寒功能基因的表达 可能会抑制苜宿其它优良特性, 因此苜宿抗寒基因工程 任重而道远。

\section{5. 结论与展望}

紫花苜宿越冬期低温造成的冻害是生产上的一大威 胁, 不仅影响苜宿草地的持续高效利用, 而且限制了栽培 区域的发展。苜葆作为一种抗寒性较强的植物品种, 当受 到低温胁迫时, 其渗透调节物质等生理生化指标都会发生 明显变化, 保护性酶活性一般与萛宿抗寒性呈正相关, 渗 透调节物质中除植物受损产生的副产品外, 一般的指标值 也与苜荏抗寒性呈正相关。植物激素方面, 苜宿抗寒性是 多种激素协同作用的结果, 而根系活力则最直接的体现了 
植物越冬期的活力与生长状况。提高苜宿抗寒能力可以从 品种选择与抗寒育种、栽培管理综合技术、基因工程三个 方面入手, 帮助苜宿种植业安全越冬并获得优质高产。

伴随着中国农牧业产业结构不断调整和种草畜牧业 的迅速发展, 紫花苜宿的种植区域不断扩大, 这些区域地 形复杂, 气候多样, 苜宿越冬除需适应低温胁迫, 还面临 干旱、盐渍化等多种环境胁迫。要解决苜宿安全越冬这一 问题, 就需要对其抗逆机理进行深入研究。多年来随着对 苜宿抗寒性研究的逐步深入, 我们对其适应低温胁迫的机 理有了一定的认识, 但如何保证苜宿安全越冬才是我们的 目的所在。为了减轻冻害, 有条件的地区可以通过灌水、 覆土、调整种植制度等措施帮助苜宿安全越冬。改良育种 也是保证苜蕧安全生产的关键所在, 在引进国外优良苜宿 品种的同时, 积极培育和改良适合中国地理环境的苜宿品 种。利用传统育种技术, 中国先后于育成了多种耐寒品种, 但由于常规育种周期长、成本高, 尚不能完全满足苜宿生 产的需要。近年来分子生物学、生物化学技术不断发展, 为抗寒机理和改良育种提供了有效的技术支撑, 尽管基因 工程可迅速提高苜宿的抗寒越冬能力, 但是考虑到安全性、 稳定性等因素, 转基因苜宿大多还停留在试验阶段, 尚未 进入生产应用, 同时常规育种与现代育种技术还未有机结 合。在未来的研究中应将多层次的方法、技术结合起来, 充分关注并切实提高苜宿的抗寒越冬能力。

\section{致谢}

本文为国家自然科学青年基金项目 (51309165), 中国 水利水电科学研究院科研专项 (MK2014J05) 的阶段性成果 之一。

\section{参考文献}

［1］覃凤飞, 李强, 崔棹苔, 等. 越冬期遮阴条件下 3 个不同秋眠 型紫花苜宿品种叶片解剖结构与其光生态适应性 [J]. 植物 生态学报, 2012, 36（4）:333-345。

[2] Murata N, Ishizaki-Nishizawa 0. Genetically Engineered A lteration in the Chilling Sensitivity of lants. Nature, 1992, 356: 710-713.

[3] Webb MS, Uemura M, StePonkus PL. A Comparison of Freezing Injury in Oat and Rye: Two Cereals at the Cxtremes of Freezing Tolerance. Plantphysiology, 1994, 104(2): 467-478.

[4] Earce R S. Molecular analysis of acclimation to cold [J]. Plant Growth Regulation, 1999, 29: 47-76.

[5] 高媛, 齐晓花, 杨景华, 等. 高等植物对低温胁迫的响应研 究 $[J]$. 北方园艺, 2007 (10) :58-61。

[6] LYONS J M, RAISON J K. Oxidative activity of mito-chondria isolated from plant tissues sensitive and resistant to chilling injury [J]. Plant Physiol, 1970, 45: 386-389.
[7] 孙启忠, 王育青, 侯向阳. 紫花苜宿越冬性研究概述 [J]. 草 业科学, 2004, 21（3）:21-25。

[8] Bertamini M, Muthuchelian K, Rubinigg M, et al. Low-night TemPerature Inereased the Photoilthibition of Photosynthesis in GraPevine (Vitisvinifera L. cv. Riesling) Leaves [J]. Environ Exp Bot, 2006, 57: 25-31.

[9] 崔国文, 马春平. 紫花苩宿叶片形态结构及其与抗寒性的关 系 [J]. 草地学报, 2007, 15 (1) : 70-751。

[10] Viands D R. Variability and selection for characters associated with root regeneration capability in alfalfa [J]. Crop Science, 1998, 28: 232-236.

[11] Stout P C, Hall J W. Fall growth and winter survival of alfalfa in interior British Columbia [J]. Can. J. PlantScience, 1989, 69: 491-499.

[12] 曹致中, 贾笃敬, 汪胥. 根藥型苜宿的引种和育种 $[\mathrm{J}]$. 中国 草地, 1990, (4) : 25-301。

[13] Schwab P M, Barnes D K, Sheaffer C C. The relationship between field winter injury and fall growth score for 251 alfalfa cultivars [J]. Crop Science, 1996, 36: $418-426$.

[14] Campbell T A, Bao G, Xia Z L. Completion of the agronomic evaluation of Medicago ruthenica(L.) germplasm collected in Inner mongolia [J]. Genetic Resources and Crop Evolution, 1999, 46(5): 477-484.

[15] Viands D R. Variability and selection for characters associated with root regeneration capability in alfalfa [J]. Crop Science, 1998, 28: 232-236.

[16] DaMatta FM, Ramalho J D C. Impacts of Drought and Temperature Stress on Coffee Physiology and Production: a Review [J]. Brazilian Journal of plant Physiology, 2006, 18 (1) : 55-81.

[17] Gerloff E D, Stahmann M A. Soluble proteins in alfalfa related to cold hardiness $[\mathrm{J}]$. Plant Physiology, 1967, 42(7): $213 \sim 217$.

[18] 冯昌军, 罗新义, 沙伟, 等. 低温胁迫对苜宿品种幼苗SOD、 POD 活性和脯氨 酸含量的影响 $[\mathrm{J}]$. 草业科 学, 2005, 22 (6) :29-32。

[19] 梁慧敏, 夏阳. 苜宿抗寒性及根菜性状的表现与过氧化物酶 同工酶关系的研究 [J]. 草业学报, 1998, 7 (4) : 55-60。

[20］杜秀敏, 殷文璇, 张慧, 等. 超氧化物歧化酶 (SOD) 研究进展 [J]. 中国生物工程杂志, 2003, 23 (1) : 48-50。

[21] 罗新义, 冯昌军, 李红, 等. 低温胁迫下肇东苜宿SOD、脯氨酸 活性变化初报 [J]. 中国草地, 2004, 26 (4) :79-81。

[22］邓雪柯, 乔代蓉, 李良, 等. 低温胁迫对紫花苜宿生理特性影 响的研究 $[J]$. 四川大学学报 (自然科学 版）, 2005, 42(1):190-194。 
[23] 王曙阳, 李景华, 姜伯玲, 等. 12C6+离子辐照对苜宿M1低温 胁迫存活率、过氧化氢酶及过氧化物酶活性的影响 $[\mathrm{J}]$. 原 子核物理评论, 2014, 31 (3) : 411-415。

[24] 简令成. 生物膜与植物寒害和抗寒性的关系 [J]. 植物学通 报, 1983, (1) : 17-22。

[25] Smith D. Winter injury and the survival of forage plants [J]. Herb Abstr, 1964, (33) : 203-209.

[26] 韩瑞宏, 卢欣石, 余建斌, 等. 苜宿抗寒性研究进展 [J]. 中国 草地, 2005, 27 (2): 60-64。

［27］陶雅, 孙启忠. 不同紫花苜宿品种可溶性糖、全氮、丙二醛 含量动态变化及其与抗寒性关系研究 [J]. 中国农业科技导 报, 2008, 10 (S1) :56-60。

[28] 王英哲, 任伟, 徐安凯, 等. 低温胁迫下紫花苜宿对外源SA和 ABA的生理响应 $[J]$. 华北农学报, 2012, 27 (5) : 144-149。

[29] 刘志洋, 宫书, 陈曦, 等. 低温处理对六种宿根花卉根系活力 的影响 [J]. 北方园艺, 2009, (7) :201-203。

[30] 康俊梅, 李燕, 沈静, 等. 低温胁迫对野牛草幼苗渗透调节物 与根系活力的影响 [J]. 中国畜牧兽医, 2010, 37 (12) : 18-21。

[31] 许怡玲, 遇文婧, 周玉迁, 等. 低温胁迫对玉穊根系活力的影 响 $[J]$. 林业科技, 2010, 35 (3) : 55-58。

[32] 徐呈祥. 提高植物抗寒性的机理研究进展 [J]. 生态学 报, 2012, 32 (24) :7966-7980。

[33] 徐春波, 王勇, 周赵海霞, 等. 冷诱导转录因子AtCBF1转化紫 花苜宿的研究 $[J]$. 草业学报, 2012, 21 (4) : 168-174。

[34] Brouwer D J, Duke S H, Osborn T C. Mapping genetic factors associated with winter hardiness, fall growth and freezing injury in autotetraploid alfalfa $[\mathrm{J}]$. Crop Science, 2000, 40(5): 1387-1396.

[35] McKersie B D, Murnaghan J, Jones K S, et al. Iron-superoxide expression in transgenic alfalfa increases winter survival without a detectable increase in photosynthetic oxidative stress tolerance [J]. Plant Physiology, 2000, $122(4)$ : 1427-1437.

[36] Samis K, Bowley S, McKersie B. Pyramiding Mn-superoxide dismutase transgenes to improve persistence and biomass production in alfalfa [J]. Journal of Experimental Botany, 2002, 53(372): 1343-1350

[37] 田小霞, 孟林, 毛培春, 等. 低温条件下不同抗寒性薰衣草内 源激素的变化 [J]. 植物生理学报, 2014, 50 (11) : 1669-1674。

[38] 翟飞飞, 韩蕾, 李伟, 等. 田间低温下多年生黑麦草再生株系 的抗寒性研究 [J]. 核农学报, 2015, 29(5):0961-0971。

[39] 刘敏, 龚吉荵, 张梓瑜, 等. 北方干旱区优良牧草抗旱性和抗 寒性研究进展 $[\mathrm{J}]$. 西北农林科技大学学报 (自然科学 版), 2015, 43(3): 56-62。

[40] 王世发, 黄淑兰. 北方旱寒区白菜型冬油菜品种抗寒性与适 应性分析 $[J]$. 北方园艺, 2015, (04) : 58-60。

[41] 王涛, 王晓楠, 王明芳, 等. 低温下冬小麦水分含量的变化与 抗寒性鉴定 $[J]$. 作物杂志, 2015, 1:61-66。

[42] 刘鹏, 曹林, 王利华, 等. 低温胁迫下外源水杨酸对栝楼幼苗 抗寒性影响 $[\mathrm{J}]$. 浙江师范大学学报 (自然科学 版), 2015, 38(1):9-14。 